\title{
Hospital reimbursement and readmissions. Norway 2002, 2005 and 2008
}

\author{
S O Petersen \\ From 26th Patient Classification Systems International (PCSI) Working Conference \\ Munich, Germany. 15-18 September 2010
}

\begin{abstract}
Introduction
Activity-based financing of acute somatic hospitals was introduced in Norway in July 1997, succeeding financing by frame budgets. The financing is based on estimated costs per DRG and total number of DRG points produced. Since 2006, the reimbursement to the hospitals has been 40 percent of the total estimated costs. This is a strong incentive for the hospitals to maximize the patient volume and hence the number of DRG points. The mean length of stay at Norwegian hospitals has been decreasing annually, from 5.67 days in 2002, to 5.15 days in 2005, and to 4.75 days in 2008. During the same period, the readmission rate has increased from 10.24 in 2002 to 11.77 in 2008.

The aim of this study is to estimate reimbursements associated with readmissions. We are going to study changes from 2002 until 2008, and investigate if there was any difference between surgical patients and others.
\end{abstract}

\section{Methods}

The data used in this study is individual patient data from 55 acute somatic hospitals in Norway for the years 2002, 2005 and 2008. The data are registered at the hospitals and collected, verified and provided by the Norwegian Patient Register. An emergency admission of a patient 30 days or less since the last discharge is called a readmission.

Readmissions are calculated based on a unique identification number given to all patients. The number is different from hospital to hospital, and changes each year. For this reason, it is not possible to compare data for the same patient from two subsequent years. For example, we do not know if an admission in January was a readmission of a patient discharged in December the previous year. Hence, the data used cover the

SINTEF, Trondheim, Norway period February-December for each of the three years studied. Day care and day surgery are excluded from the study.

\section{Results}

The total number of DRG points for readmitted patients increased by a percentage of 36.2 during the period 2002-2008, more than twice that of the increase of the total number of DRG points for all patients (17.1 per cent). Patients grouped into a surgical DRG had fewer readmissions than other patients (in 2008, the readmission rate was 6.63 compared to 13.37$)$. The increase in DRG points (2002-2008) was 29.7 per cent for surgical patients not readmitted, and 53.1 for readmitted surgical patients. For other patients, the percentages were 6.7 (not readmitted) and 31.4 (readmitted). Of the total increase in DRG points from 2002 to 2008, a percentage of 26.3 was due to an increase of readmissions.

\section{Conclusions}

The readmission rate is increasing annually, and since the average cost-weight is higher for readmitted patients than others, more than 25 percent of the increased number of DRG points is due to the increase in readmissions. This may be explained as a result of the activity-based payment system, where the hospitals regularly have to meet demands of efficiency and increased patient volume.

Effects of the activity-based payment system may be too early discharge of patients, more readmissions, and a need for increased reimbursement from the state. Thus, more and more financial resources are transferred to the hospital sector. And more and more of these resources are used to treat the same patient more than once. Since surgical patients, on an average, have a 
higher cost-weight than other patients, the increase in reimbursement is more visible for surgical patients than others.

Published: 6 October 2010

doi:10.1186/1472-6963-10-S2-A14

Cite this article as: Petersen: Hospital reimbursement and readmissions.

Norway 2002, 2005 and 2008. BMC Health Services Research 2010

10(Suppl 2):A14.

Submit your next manuscript to BioMed Central and take full advantage of:

- Convenient online submission

- Thorough peer review

- No space constraints or color figure charges

- Immediate publication on acceptance

- Inclusion in PubMed, CAS, Scopus and Google Scholar

- Research which is freely available for redistribution 